\title{
Study on the Forging of Enterprise Learning Ability Based on the Learning Cycle Theory
}

\author{
Bingfeng Liu \\ School of Business Administration, Jing De Zhen Ceramic Institute, Jiangxi Province, China \\ txcf2000@163.com
}

Keywords: Enterprise reform; Learning ability; Core advantage; Learning cycle theory; Ability forging.

\begin{abstract}
The basis of learning ability is the ability to extract. Is able to organize the individual good experience, a good way to sum up, and on this basis to find the law in order to guide the organization of the future work, this action is forging. But most enterprises have not formed the system of learning ability forging method. The learning ability of enterprises is the driving force and necessary condition for the enterprise to gain the competitive advantage. This paper discusses the enterprise learning ability concept and the correlation dimension, and comments on the learning ability forging of the related theoretical models and focuses on the study of enterprise learning ability forging way, in order to enterprise management research to provide reference. In order to continuously improve the learning ability of the enterprise, it is necessary to create a good environment and conditions, to create a learning oriented enterprises, enhance the competitiveness of enterprises and sustainable development.
\end{abstract}

\section{Introduction}

Generally speaking, the formation of the core competence of enterprises should experience the process of accumulation and integration of unique resources, knowledge and technology. Through this series of effective accumulation and integration, so that enterprises have a unique and lasting competitiveness. Learning ability is the fundamental to develop new competitive advantage. Peter Senge pointed out that the only lasting advantage in the future is to have the ability to learn faster than your competitors. According to learning cycle theory, the learning process is a cycle, the organization of information and knowledge through a series of produce, flow and use in the organization, so that the organization constantly adapt to the needs of internal and external environment changes, to maintain lasting vitality.

\section{Enterprise Learning Ability: Concepts and Dimensions}

The Concept of Enterprise Learning Ability: A Perspective of Social Cognition. According to the learning cycle theory, the basic point of view, is the enterprise and individual and group as a collection of cognition, and those who, collection of the individual or individuals in a social or business context interaction in the process of perception, analysis, planning and choice, corporate members and department or team group and a corporate learning is in the process of constantly revised their cognitive model, the formation of corresponding cognitive map, or personal or corporate mental map, which became their analysis of environmental change and based on its own meaning. And this kind of analysis guides their choice of action. They from the feedback from the environment and the subjective interpretation of the feedback information to obtain more information about action appropriate or not, correction and self-examination, correction or adjustment action, namely the repeated positioning and selectivity, to make the action will continue to point to the target [1].

In general, companies can predict the possible outcome of the new action and adjust the appropriate action strategy or business strategy, use of opportunities and shortcuts, to cope with the 
crisis and to face learning disabilities, or the idea of innovation. Enterprises can successfully complete the above learning process has the strength and level, is the learning ability of enterprises.

The Dimensions of Enterprise Learning Ability: the Key Link of Ability Forging. From the theoretical and practical point of view, the learning ability of the enterprise can be observed and measured. The comprehensive measurement index of enterprise learning ability can be used as a comprehensive index of the enterprise which is close to the learning enterprise. Might be there are different from traditional enterprises to study the performance and characteristics of enterprise transformation, but the most fundamental is the overall capacity of the enterprises to deal with the turbulent environment changes in an enterprise constantly tends to learning type enterprise in the learning process, the ascension of the enterprise learning capability, and this is also the enterprise face a variety of learning problems, overcome or remove barriers to learning fundamental way. An enterprise that does not have the learning ability is unable to face the problem, breaks through the barrier [2].

To treat and analyze the forging of learning ability, we must consider the measurement index of enterprise's learning ability. A person's learning ability is made up of a lot of individual ability, these individual ability is ability factor. Similar to the individual learning ability, the learning ability of the enterprise is composed of many kinds of ability factors, namely, the learning ability of the enterprise can be seen as a form of different aspects or dimensions. If we can clearly identify these dimensions, namely exactly defining enterprise want to enhance the learning ability of the specific dimensions, then we may not only develop a complete measuring enterprise learning indices or parameters of system, can also through continuous adjustment of the learning action of the enterprise to enhance their ability to learn and to make it more suitable for enterprise's specific needs.

\section{Enterprise Learning Ability Forging: Theoretical Analysis}

The thinking of the learning ability of forging enterprises will provide us with the direct operation basis of forging the path to overcome and eliminate the learning obstacles or problems by using the enterprise learning ability of the enterprise [3]. On how to forge the enterprise learning capability, clear we need to do something important, but more important is clear we do, that is how we can change their attitude, behavior and corporate structure to enable enterprises to learning ability change?

From the current research literature, the current comparison of the representative theory is Peter Senge's five practice model, Dafydd's three plate construction model and Neves's three process cycle model. These typical models on the learning ability of forging enterprises, from different angles for us to provide a theoretical basis for how to forge the ability of enterprises to learn [4]. But these models did not really from the enterprise learning ability forging process pointed out that the forging process and other business process should be in the end how linked together, in order to constitute a learning enterprise overall and continuous process [5].

Therefore, it is necessary to on the basis of the model, the process of the linkage of these pointed out that in order to enterprises from the perspective of the overall know linkage between the enterprise ability forging and other business processes and interactions, and thus more conducive to promoting the learning type enterprise to construct the whole process [6].

Only clear the enterprise learning ability forging in the construction of learning type enterprises in the overall position, the enterprise will know from the above aspects to forging enterprise learning ability, what factors will lead to what influence on the performance of the company, then such enterprise learning ability forging made not only is effectively to enhance the capacity, and is really targeted, not for forging and forging. Because in terms of global significance, forging enterprise ability to learn by themselves and not to, it is only in order to improve the business performance of a process [7]. So we need in learning ability of forging enterprises, enterprises guidance framework for action as the guide, according to the enterprise strategy formulated specific learning strategies, using the corresponding learning tools, under the command of these preconditions, can we gradually 
operation to push the development and implementation of the important link of the forging of the enterprise learning capability of the theory model of the conception [8].

In this view, such as enterprise learning ability in learning style transformation ability, companies often in this regard is incompetent, not easy to accept the new mode of action and the innovation of enterprise system, this does not completely are due to the enterprise learning ability is low because of, and more likely to be enterprise way of thinking is too mechanical, or is the enterprise structure rules are too rigid, or is the simplification of the learning method advocated in human resource management and enterprise performance management, or is to manage the quality of service does not require the member enterprises of various ways of learning and the frequent conversion, and so on. These aspects of the enterprise process may cause the enterprise is difficult to forget to learn to give up or forget the old way of learning. The ability to learn is the key to solve these problems, but it is not the only one. Because companies must also know what ability needs to be used where, must know to make use of these abilities reach enterprise performance will encounter problems and obstacles in where, and then to think about solutions to solve or over obstacles. Thus, forging a good corporate learning ability to be used in the most need to use the problem on.

Therefore, there are two ways of thinking about the learning ability of forging enterprises: one direction is to keep the existing learning methods, but try to improve the effectiveness of the enterprise performance. This is a linear increase, gradual or improved learning; another direction is changing the mode of learning, which requires enterprises in the combination of various factors on the possible learning orientation make new choices, namely, innovation, and system innovation of enterprise structure and system, in order to obtain the support of the new way of learning, the corresponding enterprise system conditions guarantee. Obviously, this is a kind of innovative learning, is radical or revolutionary learning. This is not only by the enterprise learning ability forging this single path can be directly reached [9].

\section{Enterprise Learning Ability Forging: Practical Ways}

The research literature of the study type enterprise shows that almost all the research are advocating a common belief: the learning ability of the enterprise can be forged by the standard technology and method. Here implies two propositions: one is the learning ability of the enterprise can be forged or promotion, which has been in the enterprise related learning theory is each subject and the same subject study of the different ideas of a large number of research literature results confirmed; the second is the enterprise learning capability can be used to design strategy and technical route or specific methods to reconstruct or upgrade. That is to say, there are two aspects in the theory of learning tool, and strategy or construction approach to the construction of learning oriented enterprises [10].

In reality, the real forging enterprise learning ability, must experience the birth of enterprise learning ability, stimulate, upgrade and recycling of three different but continuous forging stage.

The Birth of Enterprises Learning Ability. Although the learning ability of the enterprise is not the linear addition of the individual learning ability, but it is based on the learning ability of the individual enterprise members. The learning ability of enterprise is based on the individual learning ability, which is based on the integration and development of the enterprise. So, the first step in learning ability of the forging enterprises is to tracing the origin, from source forge. Soon the starting point and the foothold is first put in the member enterprises of individual learning ability cultivation and development and system integration.

The cultivation of individual learning ability in the final analysis is to have a good sense of self, high learning enthusiasm, strong learning will and breakthrough the conventional creative ideas. Many individuals in the enterprise learning ability has, from the enterprise learning ability "germination period" is not far away. Learning atmosphere, enthusiasm, courage, courage and confidence, perhaps to others is contagious, the enterprise has the very strong learning ability of the members of the will in an imperceptible impact on the surrounding people. 
The Stimulation of Enterprise Learning Ability. The second step of learning ability is to stimulate the learning ability of enterprise based on the integration of individual learning ability. The main ways include: first, create the enterprise culture environment which is conducive to the expansion of learning ability. Fully inclusive of dissent, advocating innovation, cooperation in a win-win open and fair competition and equality but modest fear of authority, magnanimous philosophical, self-examination, face the controversy and shouldering responsibility of corporate culture, strong in corporate culture and social psychological space for enterprises to learn learning ability to develop and stimulate provides the most fundamental growth soil. Two is designed to be conducive to the ability to forge the structure of the enterprise. Three is to optimize the enterprise information processing mechanism. Access to information, links, transmission, use and protection give full play to the advantage of modern information technology, using interactive multimedia communication and dialogue in Internet technology, online information processing, video conferencing and other various information processing mechanism, realize enterprise members in the virtual spatial learning, make the enterprise knowledge sharing and information exchange to achieve full freedom realm, to the enterprise by the learning ability of modern science and technology and the network technology of forging have been proposed with the simultaneous development of the network technology of the new requirements. Four is a reasonable arrangement of enterprise incentive system. The incentive is to encourage and cheer people up, energetic and meaning, which is to inspire people's motivation, the induction of human behavior, making it play an intrinsic potential, to achieve the pursuit of the goal of working process, that is, we usually say to mobilize people's enthusiasm of meaning. Five is to play a good corporate learning facilitator. In the enterprise to construct a balance, so that people have the ability to seek a dynamic balance between the continuation of the status quo and the creation of the future.

The Improvement and Reconstruction of Enterprises Learning Ability. Forging enterprise learning ability of the third step is to have been inspired by the enterprise learning ability to be promoted. The typical way to improve the learning ability of the enterprise is team learning. It aims to focus on the ability of business members to achieve common goals. Cooperative learning has the amazing potential, the collective can achieve more insight than the individual, more intelligent, the group's IQ can be far greater than the individual's IQ. Through in-depth talks and open discussion of the two forms of conversation, you can forge the ability to continue to create learning.

At the same time, forging enterprise learning ability should be in is pregnant, inspire and promote the competition ability based on further temper more high level and the strength of the process. This is mainly based on the theoretical model of enterprise learning ability forging those important aspects, links and factors to be focused and targeted ability to strengthen. For example, strive to make every level in the enterprise all learning self-transcendence, the establishment of a common vision of the enterprise, so that enterprises get creative tension, resulting in a new high degree of enterprise learning ability.

\section{Summary}

Finger \& Brand (1999) distinguish the enterprise learning capability of six dimensions: individual learning ability and collective learning, structure learning ability, culture learning ability, promote and enhance the learning effect of the enterprise work ability and leadership skills. This paper examines the forging learning ability the operation way, is established on the basis of the theory that enterprises can use of the ability and capacity factor strengthening and forging enterprise learning ability, and ability through the corresponding technical and practical observation index system to evaluate specific enterprise learning.

\section{References}

[1] Garvin, D.A. Learning in action: A Guide to Putting the Learning Organization to Work, Boston, MA: Harvard Business School Press, 2000. 
[2] Senge P M, Sterman Jd. Systems Thinking and Organizational Learning-Acting Locally and Thinking Globally in the Organization of the Future, European Journal of Operational Research, Vol.59 (1992)No.1, p p: 137-150.

[3] Watkins, K.E., Marsick, V.J., Towards a Theory of Informal and Incidental Learning in Organizations, International Journal of Lifelong Education, Vol.11 (1992) No.4, pp: 287-300.

[4] Garvin DA, Edmondson AC, Gino F, Is Yours a Learning Organization? Harvard Business Review, Vol. 86(2008) No.3, pp: 109-112.

[5] Goh S C, The Learning Organization: an Empirical Test of a Normative Perspective, International Journal of Organization Theory \& Behavior, Vol.4 (2001) No. 3, p p: 329-355.

[6] Nonaka, the Knowledge Creating Company: How Japanese Company Create the Dynamics, New York: Oxford university Press, 1995.

[7] Antero Honkasalo, Occupational Health and Safety and Environmental Management Systems, Environmental Science \& Policy, No.3 (2000), pp: 39-45.

[8] Jacqueline L. Joann Nambe, Determinants of Corporate Growth Opportunities of Emerging Firm, Journal of Economic and Business, 2002(5):73-93.

[9] Carayannis. E.G .Preston .A and Awerbuch. S (1996), Technological .Architectural Innovations and the Virtual Utility Concept, IEMC96, pp: 94-105.

[10] Torbjon Rundmoa, Andrew R. Hale, Managers's Attitudes towards Safety and Accident Prevention. Safety Science, Vol.41 (2003), pp: 557-574. 